\title{
Para além da virtualização: a educação a distância e a revolução comunicacional no mundo contemporâneo
}

\author{
Beyond virtualization: distance education and \\ communication revolution in the contemporary world
}

Ana Raquel Abelha Cavenaghi*

Richard Gonçalves André**

\section{Resumo}

$\mathrm{O}$ artigo tem por objetivo sugerir que a educação a distância (EAD) é parte de um paradigma comunicacional em processo de estruturação no mundo contemporâneo. Ela deve, portanto, ser pensada a partir de elementos mais ou menos específicos e irredutíveis às questões apresentadas pela educação presencial. Como se trata de fenômeno historicamente recente, as proposições teóricas atuais parecem insuficientes para compreender a questão. Mesmo assim, utilizam-se, neste texto, certos constructos voltados especialmente para os conceitos de linguagem e convergência de mídias, bem como o conceito de paradigma. É necessário pensar a EAD considerando sua natureza específica, apresentando, em primeiro lugar, o papel dos sujeitos do conhecimento,
Abstract

The paper intends to suggest that the distance education (DE) is part of a communication paradigm in structuring process in the contemporary world. It is highlighted that it must, therefore, be considered from more or less specific elements irreducible to questions presented by regular education. As it is a recent historical phenomenon, the current theoretical propositions seem insufficient to understand the issue. Even so, we utilize, in this text, some constructs related especially to the concepts of language and media convergence, as well as the concept of paradigm. The discussions point to the need to think DE considering its specific nature: the role of subject of knowledge, emphasizing the triadic action of professors, tutors and students

\footnotetext{
${ }^{*}$ Doutoranda em Educação, Universidade Estadual de Campinas (Unicamp). Departamento de Letras Estrangeiras Modernas da Universidade Estadual de Londrina (UEL). anaracavenaghi@ hotmail.com

**Departamento de História, Universidade Estadual de Londrina (UEL).richard_historia@hotmail. com
} 
ressaltando a atuação triádica de professores, tutores e alunos e enfatizando o processo de autonomia destes; em segundo lugar, embora gerada num novo paradigma comunicacional, a EAD deve resguardar o tempo para maturação das ideias na construção do conhecimento, mesmo num mundo de aceleração na circulação informacional.

Palavras-chave: educação a distância; paradigma; comunicação. and stressing their process of autonomy; though generated in a new communicational paradigm, DE must preserve the time to maturation of the ideas in the construction of knowledge, even in a world marked by acceleration of informational flow.

Keywords: distance education; paradigm; communication.

Como sugere o pesquisador espanhol Jesús Martín-Barbero (2008), no mundo contemporâneo, especialmente a partir do final do século XX, os saberes passaram a circular de forma diferenciada quando comparados aos conhecimentos de natureza logocêntrica. Os dados disponíveis na Internet, que podem transcender a linguagem verbal, são interligados por uma rede de $h i$ perlinks fragmentados e descentralizados que remetem o usuário a diferentes locais do universo virtual, como blogs, sites e redes sociais. Os dados são potencialmente acessados por diferentes dispositivos, tais como laptops, desktops, smartphones, tablets e videogames, entre outros, podendo ser salvos em mídias físicas, como hard discs e pendrives, ou mesmo armazenados nas "nuvens" e visualizados por streaming, sistema que dispensa o salvamento de arquivos fisicamente, transmitindo seus conteúdos em tempo real (ver, por exemplo, serviços como o Dropbox e o One Drive; no caso de filmes, o Netflix e, em relação aos games, o Steam e a Gaikai) (André, 2013). Trata-se de um variado repertório de novos conceitos e instrumentos que marcam essa revolução comunicacional, o que se manifesta, principal mas não unicamente, na digitalização e virtualização informativa em contraposição aos artefatos de cunho analógico, que não dispensam o suporte material. Eles não desapareceram, na medida em que, para ilustrar, os ebooks não necessariamente substituíram os livros em papel. De qualquer forma, na atualidade, a profunda alteração nos modos de produção, circulação e consumo do saber perpassa diferentes dimensões da sociedade.

As variadas formas da chamada educação a distância (EAD), desde os telecursos aos cursos online desenvolvidos, sobretudo, pela plataforma Moodle, 
parecem fazer parte da revolução comunicacional indicada, uma vez que pressupõem repensar a educação formal por intermédio de novas linguagens e mídias, tendo como uma de suas manifestações a virtualidade. Considerando essas questões, o presente artigo propõe um exercício de compreensão no tocante às correlações entre a EAD e o contexto comunicativo em foco, chamando a atenção para a necessidade de redimensionar os elementos da EAD a partir das demandas desse novo paradigma comunicacional e, também, educacional. Por isso, no decorrer desta reflexão, sugere-se que, mais que "transplantar" os postulados da educação presencial para a EAD, é necessário problematizá-los e pensá-los de acordo com as novas questões em jogo.

\section{Por QUE ABORDAR O EVIDENTE?}

A revolução comunicacional em foco perpassa diferentes facetas do cotidiano, de forma que parece impossível um indivíduo viver à margem dela em pelo menos algumas de suas dimensões. Responder e-mails, processar transações bancárias ou mesmo fazer um pedido num restaurante, aspectos mais ou menos comuns na sociedade atual, envolvem a operacionalização de uma rede de dados e dispositivos conectados ao fenômeno em questão, de forma a torná-lo evidente no dia a dia. Contudo, do ponto de vista epistemológico, essa evidência constitui um primeiro paradoxo, já que muitos pesquisadores parecem ignorá-la, rejeitando as novas mídias de diferentes formas, seja concebendo-as como fontes de corrupção do sujeito e responsáveis pelas mazelas sociais, seja apropriando-as de forma insuficiente aos campos do saber (André, 2013).

Os historiadores têm quase sistematicamente ignorado a discussão, que tem sido relegada a um presente demasiadamente imediato para fazer parte de suas reflexões, como se os elementos da chamada história do tempo presente não fossem parte de seu território de preocupações (Chauveau; Tétart, 1999). Os sociólogos, por sua vez, foram pioneiros ao lidar com os objetos midiáticos, lembrando as contribuições dos intelectuais ligados à Escola de Frankfurt, como Theodor Adorno (1986). Entretanto, a abordagem da indústria cultural, que compreende a mídia como subproduto cultural voltado para a alienação das massas, parece limitada diante da complexidade do fenômeno, a ponto de o semioticista italiano Umberto Eco (1993) denominar perspectivas teóricas do gênero como "apocalípticas". 
Uma exceção a essa lacuna na produção de conhecimento é o campo da comunicação e da semiótica, que tem buscado compreender o fenômeno comunicacional para além da perspectiva apocalíptica, integrando-a ao universo de reflexão. Além de Eco, é possível ressaltar os trabalhos de Lucia Santaella e Winfried Nöth (2008), que, fundamentados, principalmente, nos conceitos propostos pelo semioticista norte-americano Charles Sanders Peirce, enfatizam a multiplicidade de linguagens que perpassam o mundo contemporâneo. A linguagem, da perspectiva dos autores em foco, transcenderia as estruturas verbais e orais, que, não obstante importantes, compõem apenas uma de suas dimensões. Os fenômenos linguísticos englobariam, de acordo com Santaella (2005), três matrizes, envolvendo o som, a imagem e o verbo. Além disso, mais que compreendê-las separadamente, seria necessário, atualmente, perceber suas relações transversais, porquanto a virtualidade envolva interfaces linguísticas que não podem ser ignoradas, como observam Santaella e Nöth (2008), o que será denominado, a partir daqui, convergência das mídias. Basta pensar, por exemplo, nos jogos eletrônicos que demandam a atenção do gamer aos aspectos gráficos, sonoros e verbais, isso para não falar da interatividade que constitui um dos eixos principais da revolução comunicacional que compreende o objeto do presente artigo. Isso possui implicações importantes para a EAD, como será discutido adiante.

Outro conceito importante para lidar com o fenômeno em questão é o termo paradigma, cunhado pelo filósofo da ciência norte-americano Thomas Kuhn (1998). Compreende-se, pelo constructo teórico, um conjunto de postulados e, portanto, pressupostos comuns que norteiam a construção de determinados campos do saber, que desempenham o papel de modelo ou matriz para sua elaboração. Afirma-se, no presente artigo, que a Educação a Distância (EAD) está inserida numa revolução comunicacional na medida em que o que parece estar em jogo não é apenas uma transição do analógico para o digital, do presencial para o virtual, mas a estruturação de uma modalidade educativa formal fundamentada num paradigma diferenciado, não necessariamente calcado no esquema cartesiano-newtoniano que tem orientado a educação nos últimos séculos, como observa Martín-Barbero (2008). Postulados clássicos, como o reducionismo científico e o império da palavra sobre os diferentes tipos de linguagem, não são pertinentes para fazer jus à complexidade inerente à $\mathrm{EAD}$, demandando-se um alargamento das fronteiras teóricas. De qualquer 
modo, não se ignora que, tal como a EAD insere-se no contexto histórico de uma revolução comunicacional, esta se liga, de forma mais ampla, à estruturação de um paradigma que, malgrado não consolidado, vem se desenvolvendo desde, pelo menos, os postulados da física quântica no século XX, que problematizaram as relações entre sujeito e objeto no processo de construção do conhecimento científico (cf. Köche, 1997; Capra, 2002; Santos, 1988).

Nesse sentido, parte dos debates em torno da EAD, pelo menos no senso comum, tem se desenvolvido a partir de um falso problema, que compara qualitativamente esta à educação presencial. Não cabe saber qual seria a melhor, visto que isso não acrescenta nada à reflexão propriamente dita. Apesar das perspectivas apocalípticas, a EAD provavelmente permanecerá ao longo do tempo, a menos que as mídias e os dispositivos contemporâneos se tornem obsoletos. Isso demanda discussões que contribuam para sua compreensão como fenômeno transdisciplinar e para a melhoria de seu processo organizacional e de concepções teórico-metodológicas. Paralelamente, a virtualização das instituições de ensino e aprendizagem aparentemente não acabará com a educação presencial (mesmo porque elas podem ser desenvolvidas no interior de uma mesma instituição), assim como a leitura de $e$-books não eliminou as tradicionais práticas de leitura. Apesar de ambas poderem trocar experiências, repensando a si próprias de forma salutar, há questões específicas que remetem à compreensão dessas dimensões pedagógicas no interior de seus respectivos paradigmas comunicacionais.

\section{Questões DE PARADIGMA}

Nos últimos dois séculos, a educação presencial tem sido desenvolvida a partir do paradigma newtoniano-cartesiano, como observa Martín-Barbero (2008). Em primeiro lugar, pode-se ressaltar a ênfase na razão, convertida em epicentro ontológico segundo a máxima do filósofo francês René Descartes “penso, logo existo". Na sociedade ocidental, o principal índice da racionalidade tem sido a palavra escrita, a ponto de ela ter sido transformada no parâmetro clássico que dividiria as sociedades históricas, dotadas de escrita, daquelas a-históricas ou ágrafas (Moniot, 1995), que se baseariam apenas em sua materialidade, reduzida à condição supostamente primitiva de fetichismo (Droogan, 2013). Isso levou a escola a enfatizar o papel do verbo como matriz 
do conhecimento científico, seja no que se relaciona ao discurso do professor (não coincidentemente o agente do conhecimento na educação tradicional, como critica Paulo Freire, 2000), seja no tocante ao papel do livro como recipiente quase sagrado do saber. Não é casual que, no quadro de disciplinas escolares, as disciplinas de peso têm sido português e matemática (lembrando outro traço do paradigma clássico, a linguagem objetiva e, portanto, matemática), ao passo que as artes, incluindo-se genericamente a música e as expressões visuais, lutam para ganhar espaço institucional (ver, no caso da música, as reflexões de Silvia Cristina Gonçalves Moreira, 2012). Aliás, de forma estereotipada, o aluno "rebelde" é aquele que desenha e que toca, não aquele que escreve e calcula. As universidades, sobretudo as licenciaturas, pouco mudaram em relação ao eixo centrado no texto escrito, sendo as outras linguagens consideradas secundárias em relação ao universo logocêntrico. Desenho seria coisa do design e o som pertenceria à esfera da música, que, diga-se de passagem, não se encaixariam na matriz clássica das ciências "duras".

Outro elemento relacionado ao paradigma cartesiano-newtoniano diz respeito ao reducionismo científico, que postula a divisão do objeto de pesquisa em partes, fracionadas das mais simples às complexas. No universo educacional, isso implicou a multiplicação de disciplinas que versam sobre diferentes campos do saber, mas que não necessariamente dialogam entre si de forma transversal. Embora, na educação básica, os Parâmetros Curriculares Nacionais (Brasil, 1998), desde a década de 1990, tenham enfatizado a necessidade de pensar certas questões, como a ecologia e a sexualidade, sob uma abordagem inter, multi e transdisciplinar, ou seja, compreendendo-as transversalmente, as barreiras institucionais e, mais que isso, paradigmáticas, têm dificultado a efetivação dessa abordagem sob múltiplos focos. No mundo acadêmico, salvo exceções, o quadro não tem sido diferente. Somente para citar o caso da história, a necessidade de pensá-la interdisciplinarmente, como enfatizado por intelectuais como o historiador francês Fernand Braudel, isso para não falar dos pioneiros da Escola dos Annales como Lucien Febvre e Marc Bloch (ver Braudel, 1982; Burke, 2000), tem esbarrado no que parece constituir um fechamento do campo, ensimesmado na definição do que seria ou não histórico, ignorando outras áreas do conhecimento como a semiótica e a psicanálise, relegadas ao limbo epistemológico sob a alcunha ligeira e simplista de a-historicidade. Não é coincidência, nesse sentido, que o fenômeno em foco no 
presente artigo encontre lugar periférico nas reflexões históricas. Além disso, as próprias coerções inerentes aos concursos públicos para professor universitário, geralmente exigindo como critérios a formação numa única área, dificultam institucionalmente a práxis interdisciplinar.

Entretanto, como apontado, o paradigma cartesiano-newtoniano tem apresentado, desde o início do século XX, indícios de insuficiência para explicar os problemas do mundo contemporâneo, que são de natureza complexa e resistem às tentativas de explicação de cunho reducionista. A revolução comunicacional em foco parece constituir um desses objetos complexos, sendo a EAD parte desse processo histórico, demandando um exercício de reflexão. Em primeiro lugar, o primado da palavra em relação às outras linguagens é problematizado, na medida em que a imagem, o som, a corporeidade e, atrelada a esses fatores, a interatividade ganham destaque nas mídias contemporâneas. É preciso atinar para a correlação entre essas formas de expressão, não as isolando nem atribuindo primazia a alguma delas. Os jogos eletrônicos e as redes sociais têm operado com essa noção de mídias convergentes, constituindo, atualmente, saberes que antecedem a entrada dos indivíduos nas instituições de ensino, vários deles "nativos" da era digital. Ironicamente, as escolas e as universidades têm como base a noção cartesiana, racionalista e logocêntrica que, de forma crescente, parece gerar desinteresse por parte dos alunos, mais afeitos a subirem virtualmente em torres renascentistas em games como Assassin's Creed (publicado pela Ubisoft) que a lerem materiais didáticos de história, em que textos ocupam papel central e as imagens, lugar periférico (mesmo em edições graficamente modernas, mas pedagogicamente conservadoras).

Não se pretende aqui afirmar que as plataformas da EAD devam reproduzir os jogos eletrônicos e as redes sociais. Afinal, embora informalmente eduquem (malgrado o que esteja em pauta não seja a qualidade em si da educação), porquanto gerem um processo de apropriação (Chartier, 2001) e possível reflexão (Silva, 2009), trata-se de produtos do mundo contemporâneo perpassados de outras funções, entre as quais é possível citar o mercado e o entretenimento (André, 2013). No entanto, a convergência midiática compartilhada com essas produções, que também constituem manifestações da revolução comunicacional, não deve ser ignorada. Nesse sentido, é necessária cautela para não transformar as plataformas da EAD numa mera virtualização dos 
procedimentos da educação presencial (Brasil, 2007): a pluralidade e as interfaces linguísticas, mais que o primado do verbo, devem perpassar transversalmente a EAD, dialogando com os elementos do novo paradigma educacional, e não reproduzindo sob fachada moderna os ranços do tradicional, como o fazem parte dos livros didáticos. A EAD, portanto, deve lançar mão das diferentes matrizes linguísticas, incluindo-se a corporeidade e a interatividade, correlacionando-as num todo mais ou menos coerente.

Correlacionada à questão anterior, pode-se ressaltar a transversalidade das formas de saber na atualidade que põe em xeque a divisão não comunicante de disciplinas. Embora tradicionalmente os conhecimentos prévios sejam importantes, como ressalta o educador brasileiro Paulo Freire (2000), na era digital eles são fundamentais para pensar a construção do conhecimento. De acordo com Martín-Barbero (2008), o livro deixou de ser o único eixo do saber na contemporaneidade, uma vez que o indivíduo produz conhecimentos por intermédio de diferentes canais, das wikis aos blogs, utilizando dispositivos ou gadgets como smartphones e tablets. Ao entrar em sala de aula, entretanto, os alunos lidam com disciplinas fragmentadas e não comunicantes (e, às vezes, com professores que não dialogam entre si por diferentes razões), tornando o aprendizado desinteressante quando comparado à possibilidade de fluidez do universo virtual, mesmo porque parece haver uma rejeição da mídia como suposta fonte de corrupção dos indivíduos. A EAD, pensada a partir das especificidades do novo paradigma comunicacional, pode ser estruturada sem necessariamente recair nas implicações do reducionismo científico e disciplinar. As próprias plataformas educacionais, explorando um sistema de hiperlinks que descentralizem os materiais didáticos, podem desempenhar papel importante, demonstrando como os dispositivos tecnológicos em foco, pensando em termos de dispositivos e aplicativos, assumem a função de agentes, paralelamente aos sujeitos humanos, no processo de construção do conhecimento, como propõem autores como o sociólogo e antropólogo francês Bruno Latour (1993, citado em Droogan, 2013).

\section{Desafios da EAD}

Os dois elementos apontados - a convergência de mídias e a transversalidade de saberes - constituem características do novo paradigma comunicacional 
em foco, que transcende a questão da virtualização e da digitalização, assentando-se sobre uma matriz de construção do conhecimento em processo de estruturação e que, ainda não "solidificada", talvez possa apenas ser intuída pelos observadores contemporâneos, segundo Antonio Fatorelli (2006), no tocante à fotografia digital. De qualquer forma, a $\mathrm{EAD}$, que teve respaldo legal na Lei de Diretrizes e Bases da Educação Nacional (Lei no 9.394 de 20 dez. 1996), parece ser uma modalidade de ensino gestada a partir dessa nova matriz epistemológica, não devendo apenas reproduzir o ensino presencial ou seus problemas por diferentes maneiras, mas pensar diferentes aspectos de acordo com as demandas do mundo atual. Tendo em vista a especificidade irredutível aos traços do paradigma cartesiano-newtoniano que tem caracterizado em diferentes níveis a educação presencial nos últimos séculos, serão sugeridos alguns desafios com os quais a EAD precisa lidar para sua consolidação.

Um dos primeiros desafios em jogo é a questão dos sujeitos do conhecimento na EAD. Um dos pilares da modernidade no Ocidente tem sido o indivíduo, concebido como gênio criador ou mônada independente da sociedade que historicamente o cerceia, o que tem sido questionado, sob diferentes perspectivas teóricas, por autores como Norbert Elias (1995) e Pierre Bourdieu (1998), que ressaltam a historicidade do sujeito ao reinseri-lo nos fios da sociedade. De qualquer modo, em esfera educacional, o papel demiúrgico do indivíduo foi durante muito tempo atribuído ao professor, entendido como sujeito do conhecimento (amparado, por sua vez, pela autoridade da palavra falada e escrita), tornando os alunos os receptáculos do saber. A crítica a essa postura não é nova: Freire (2000), denominando-a "educação bancária", atinando para a metáfora segundo a qual o docente depositaria os saberes no educando, ressalta que, mesmo possuindo autoridade (que não deve ser confundida com autoritarismo), o professor seria um dos agentes do conhecimento ao construí-lo com os alunos, que não seriam objetos passivos, mas agentes ativos na medida em que possuiriam conhecimentos prévios que não poderiam ser ignorados.

Embora as proposições de Freire possam ser aplicadas à educação presencial, o que é novo na EAD é o fato de essas relações serem necessariamente maximizadas, bem como a introdução de novos sujeitos do conhecimento, que, presencialmente, aparecem apenas de forma germinal: os tutores. A figura do professor permanece importante, uma vez que é o responsável pelo planejamento e a 
organização da disciplina como um todo, pensando nos conteúdos e nos métodos para desenvolvê-la. Entretanto, de forma direta, ele aparece menos considerando sua prática na educação presencial, em que as aulas devem ser ministradas rigorosamente a cada encontro. De maneira geral, na EAD, são poucas as aulas expositivas gravadas ou reproduzidas em tempo real. Nesse sentido, a autonomia do educando torna-se essencial, não apenas realizando as atividades prescritas e organizando seus estudos, mas buscando outros elementos que auxiliem na construção do conhecimento (Preti, 1996).

$\mathrm{Na}$ educação presencial também se espera que os discentes desenvolvam autonomia ao longo do processo pedagógico. No entanto, se isso não ocorrer, aparentemente, o andamento das disciplinas não é comprometido, na medida em que esse desenvolvimento pode ser simulado, mas sem uma construção qualitativa do conhecimento. $\mathrm{Na} \mathrm{EAD}$, a simulação se torna mais difícil, uma vez que a demanda pela autonomia do aluno exige que ele gerencie, por meio da autodisciplina, seu envolvimento com os cursos. Afinal, o professor não se encontra presencialmente em sua casa, cobrando sua participação a cada momento. ${ }^{1}$ Entretanto, considerando que a cultura da autonomia educativa é pouco desenvolvida na sociedade brasileira, tendo em vista que alunos e professores continuam sendo formados em contextos educacionais de cunho tradicional, um problema comum nos cursos a distância tem sido a falta de comprometimento dos discentes, o que se torna explícito em sua não participação nos fóruns, avaliações e outras atividades, redundando em uma espécie de fracasso escolar virtual.

Diante disso, paradoxalmente, os bodes-expiatórios para a situação têm sido os instrumentos digitais, como a plataforma Moodle, que seria desinteressante, complicada e mesmo esteticamente desagradável quando comparada, por exemplo, ao Facebook ou ao Twitter. Embora as plataformas possam e devam ainda ser aperfeiçoadas (como de resto acontece com qualquer instrumento em era digital, dos aplicativos às redes sociais), deve-se questionar se o problema realmente reside nos meios de acesso ou, pelo contrário, na falta de autonomia e interesse por parte dos alunos, que não têm, de forma geral, grandes problemas para lidar com softwares e hardwares mais ou menos complexos, mas que encontram uma série de empecilhos diante das plataformas educacionais. Ou seja, a ênfase recai sobre o sujeito, e não apenas sobre os meios materiais e imateriais de produção cultural, embora eles desempenhem papel 
importante. No entanto, o processo de estruturação de uma cultura da autonomia é relativamente longo, demandando o reconhecimento da importância do engajamento individual independentemente da presença de autoridades do saber dotadas de mecanismos de cobrança, geralmente calcados em recompensas e punições.

Portanto, na EAD parece haver um rebalanceamento dos papéis dos sujeitos educacionais, seja do aluno ou do professor, enfatizando a questão da autonomia como eixo para a construção do conhecimento. Como ressaltado, entretanto, a função do tutor, segundo Silveira (2005), é fundamental na estrutura de relações da $\mathrm{EAD}$, compondo um trinômio paralelamente à atuação do docente e do discente. Uma vez que a EAD é voltada para um público numericamente sem precedentes do ponto de vista da educação presencial, sendo um dos elementos que a aproximam do paradigma comunicacional discutido ao longo do presente artigo, o trabalho dos tutores torna-se imprescindível, desempenhando a função de mediador entre professores e alunos, tendo em vista que os primeiros não têm possibilidade de se relacionar diretamente com os últimos. Sem o ofício da tutoria, geralmente atuando em polos de ensino regionalizados, a EAD na escala em que é desenvolvida em diversas universidades brasileiras sequer seria possível.

Constituiria equívoco, porém, considerar o tutor apenas um reprodutor para o educando do conhecimento produzido pelo docente, o que significaria recair nas implicações da educação bancária, embora em diferente roupagem. Em primeiro lugar, porque as diferentes teorias da recepção têm ressaltado que o significado de um texto (concebido em sentido lato, aproximando-se da noção semiológica de linguagem) não se encontra apenas nele, codificado por intermédio de uma série de signos e suas relações sintáticas, mas é criado na relação que o leitor e, de forma mais ampla, o interpretante estabelece com essa estrutura sígnica (Silva, 2009). Nesse sentido, os tutores, tais como professores e alunos, seriam também sujeitos do conhecimento ao interpretarem linguagens e reconstruí-las, permitindo, por sua vez, novas interpretações e reconstruções por parte dos discentes, inserindo o processo num círculo virtualmente infinito de semiose. Em segundo lugar, embora haja certo esforço na EAD por uma padronização de métodos e técnicas de ensino, o tutor acaba desenvolvendo, ao longo de sua relação com professores e alunos, formas mais ou 
menos específicas de lidar com o público em foco, porquanto a educação possa ser a distância, mas os sujeitos envolvidos sejam profundamente humanos.

Não obstante o papel importante desempenhado pelo tutor, sua situação profissional ainda não se encontra clara nas universidades públicas brasileiras. Enquanto os professores fazem parte de uma carreira docente mais ou menos bem estabelecida, o tutor, geralmente, é um bolsista que exerce a função ao longo de determinado período, o que se assemelha a um contrato de trabalho, embora não seja isso de fato. O problema gera certa instabilidade e rotatividade no quadro de tutores, dificultando a consolidação de competências necessárias para o andamento adequado dos cursos a distância, demandando contínuas capacitações, geralmente com público diferenciado. A questão profissional é um indício da falta de clareza, na atualidade, em relação às novas exigências da $\mathrm{EAD}$, de modo que as estruturas profissionais e mesmo jurídicas não têm acompanhado no mesmo ritmo as mudanças comunicacionais e educacionais inerentes à sociedade contemporânea. Isso não é exclusividade da $\mathrm{EAD}$, remetendo às dificuldades diante das especificidades do novo paradigma comunicacional: as próprias discussões sobre o Marco Civil da Internet, que busca regulamentar garantias, direitos e deveres ligados à web, são um sintoma dessa defasagem, recordando que o acesso a ela, em nível público, ocorre desde a década de 1990, havendo, portanto, certo descompasso entre as diferentes instâncias sociais.

Outro desafio relacionado à EAD diz respeito ao tempo de maturação para a construção do conhecimento. Nos últimos anos, de forma crescente, os meios comunicacionais têm se tornado cada vez mais velozes. Mesmo os jornais editados e impressos diariamente tornaram-se demasiadamente lentos diante da dinamicidade por meio da qual as informações circulam no mundo contemporâneo, obrigando editores a buscar novas formas de pensar a imprensa escrita, embora, como afirmado, o formato papel não tenha necessariamente desaparecido. Além disso, as redes sociais e os blogs têm demonstrado, de diferentes formas, certo poder de mobilização social mais ou menos inesperado pelos observadores contemporâneos: basta lembrar o papel desempenhado pelos usuários em mecanismos como o Facebook, o Twitter e os blogs nas manifestações que perpassaram diferentes cidades brasileiras em 2013, isso para não falar de fenômenos como os chamados "rolezinhos", em que são agendados encontros em massa em certas localidades, como shoppings. O que 
está em jogo aqui não é a legitimidade dos eventos, mas o poder de mobilização das redes sociais, sem as quais, talvez, a dimensão desses movimentos seria impensável.

Apesar da velocidade na circulação das informações, cabe questionar as relações entre dinamicidade de leitura e construção do conhecimento. Malgrado o poder de mobilização das redes sociais no tocante aos fenômenos sociais contemporâneos, isso não necessariamente se correlaciona à reflexão e à maturação das ideias, transformando-as em conhecimentos mais elaborados. Um dos traços da produção de saberes em era analógica é o tempo relativamente longo para a maturação das reflexões. Contudo, a aceleração da sociedade contemporânea tem acompanhado o ritmo industrial de produção e consumo, o que trouxe implicações para a elaboração de conhecimentos, como, por exemplo, as demandas de produção no atual universo acadêmico. ${ }^{2} \mathrm{De}$ qualquer forma, voltando ao caso das redes sociais, o próprio Facebook é muito sintomático: o fluxo de dados na barra inicial de rolagem é extremamente rápido, o que varia de acordo com os contatos que o usuário possui, sendo difícil encontrar um texto ultrapassado... isto é, com alguns minutos de defasagem. Ele não é necessariamente um repositório de informações (como, em contraste, as bibliotecas digitais e outras bases de dados online), mas um sistema incessantemente retroalimentado pelos usuários que se situa num presente sempre muito imediato.

Com isso, não se pretende descartar a importância das redes sociais, mesmo porque aqueles que as conceberam, bem como seus usuários (que desempenham o papel de coautores na web 2.0, marcada pela interatividade), não têm a intenção de transformá-las num repositório que permitiria necessariamente a reflexão de ideias. O objetivo aqui, pensando nos desafios da EAD, é compreender que, não obstante as plataformas educativas possuam correlações com as redes sociais (como a conexão informativa por intermédio de hiperlinks e as mídias convergentes), na medida em que são gestadas no interior do mesmo paradigma comunicacional, elas não precisam necessariamente incorporar todos seus elementos de forma acrítica. Apesar da virtualização, uma das condições sine qua non para a construção do conhecimento continua sendo o tempo para a maturação das reflexões, que devem ser a base para a produção de um saber que não seja demasiadamente superficial, resvalando em leituras simplistas dos objetos de pesquisa. 


\section{Epílogo}

De forma geral, ao longo deste artigo, pretendeu-se apenas sugerir, em tom ensaístico, que a EAD se insere num paradigma comunicacional que transcende as questões apresentadas pelo clássico modelo de conhecimento, que tem trazido uma série de implicações para a educação. $O$ chamado paradigma newtoniano-cartesiano, pensado como matriz para a estruturação das reflexões educacionais nos últimos séculos, tem sustentado questões como o império do verbo sobre as outras formas de linguagem, relegadas ao papel de ilustração ou complemento da palavra, bem como um modelo pedagógico fragmentado em disciplinas não comunicantes que são incapazes de responder minimamente aos problemas complexos do mundo contemporâneo.

Nesse sentido, a EAD, para além de uma virtualização dos processos educativos presenciais, parece constituir traço de um novo paradigma comunicacional, inserido, por sua vez, num modelo epistemológico que vem apresentando seus primeiros indícios desde o início do século XX. Entre as questões importantes, pode-se ressaltar a necessidade de pensar as mídias convergentes, que descentralizaria o papel da linguagem verbal, integrando-a numa pluralidade de linguagens correlacionando a imagem, o som e mesmo a corporeidade, pensando-as a partir da interatividade que caracteriza os fenômenos comunicacionais do século XXI. Além disso, deve-se lembrar a transversalidade dos saberes no mundo contemporâneo, conectados por uma série de hiperlinks numa rede acessada por diferentes dispositivos.

Considerando a natureza específica da EAD, as questões e os desafios por ela enfrentados também são diferenciados, não devendo necessariamente ser pensados na perspectiva da educação presencial, não cabendo, portanto, compará-las do ponto de vista qualitativo. Dois problemas-chave foram aqui elencados: em primeiro lugar, a descentralização da figura do professor como agente pedagógico, devendo-se pensar na relação triádica desempenhada pelo docente, pelo tutor e pelo aluno, cada qual desempenhando papel em que a autonomia ocupa lugar de destaque; em segundo lugar, o tempo de maturação das ideias para a construção do conhecimento, recordando que, mesmo inserida no novo modelo comunicacional, a EAD deve preservá-lo para não redundar em conhecimentos superficiais e simplistas em torno dos complexos objetos do mundo contemporâneo. 
Este artigo não pretende ser conclusivo, mesmo porque o fenômeno em foco é historicamente recente, apresentando elementos que, não obstante o esforço de compreensão, podem ser apenas intuídos, como chama a atenção Fatorelli (2006). Portanto, abre-se espaço para o equívoco e para a incerteza que, como já afirmava o filósofo da ciência Karl Popper (1972), fazem parte da lógica da produção do conhecimento.

\section{REFERENCIAS}

ADORNO, Theodor. A indústria cultural. In: COHN, Gabriel (Org.) Theodor Adorno. São Paulo: Ática, 1986.

ANDRÉ, Richard Gonçalves. Mosaicos de saberes: mídia, educação e circularidade de saberes. Koan: revista de educação e complexidade, n.1, p.23-49, jan. 2013.

BOURDIEU, Pierre. A ilusão biográfica. In: FERREIRA, Marieta de Moraes (Org.) Usos \& abusos da história oral. Rio de Janeiro: Ed. FGV, 1998.

BRASIL. Decreto n 5.622 de 19 de dezembro de 2005: regulamenta o art. 80 da Lei ${ }^{\circ}$ 9.394, de 20 de dezembro de 1996, que estabelece as diretrizes e bases da educação nacional. Brasília: Casa Civil, 2005. Disponível em: http://www.planalto.gov.br/ ccivil_03/_Ato2004-2006/2005/Decreto/D5622.htm; Acesso em: 19 abr. 2014.

BRASIL. Lei de Diretrizes e Bases da Educação Nacional: Lei 9.394 de 20 de dezembro de 1996. Brasília: Casa Civil, 1996. Disponível em: http://www.planalto.gov.br/ccivil_03/Leis/L9394.htm; Acesso em: 20 abr. 2014.

BRASIL. Parâmetros curriculares nacionais: terceiro e quarto ciclos do ensino fundamental: introdução aos parâmetros curriculares nacionais. Brasília: MEC/SEF, 1998.

BRASIL. Referências de qualidade para a educação superior a distância. Brasília: MEC/ SEAD, 2007.

BRAUDEL, Fernand. História e ciências sociais. Lisboa: Presença, 1982.

BURKE, Peter. A Escola dos Annales (1929-1989): a revolução francesa da historiografia. São Paulo: Ed. Unesp, 2000.

CAPRA, Fritjof. O ponto de mutação. São Paulo: Cultrix, 2002.

CHARTIER, Roger. Do livro à leitura. In:___ (Org.) Práticas da leitura. 2.ed. São Paulo: Estação Liberdade, 2001. p.77-105.

CHAUVEAU, Agnès; TÉTART, Philippe (Org.) Questões para a história do presente. Bauru, SP: Edusc, 1999. 
DROOGAN, Julian. Religion, material culture and archaeology. London: Blommsbury, 2013.

ECO, Umberto. Apocalíticos e integrados. 5.ed. São Paulo: Perspectiva, 1993.

ELIAS, Norbert. Mozart: sociologia de um gênio. Rio de Janeiro: Jorge Zahar, 1995.

FATORELLI, Antonio. Entre o analógico e o digital. In: FATORELLI, A.; BRUNO, Fernanda (Org.) Limiares da imagem: tecnologia e estética na cultura contemporânea. Rio de Janeiro: Mauad X, 2006. p.19-38.

FREIRE, Paulo. Pedagogia da autonomia: saberes necessários à prática educativa. 15.ed. São Paulo: Paz e Terra, 2000.

KÖCHE, J. C. Fundamentos de metodologia científica. 21.ed. Petrópolis, RJ: Vozes, 1997.

KUHN, Thomas. A estrutura das revoluções científicas. 5.ed. São Paulo: Perspectiva, 1998.

LATOUR, Bruno. We have never been modern. Cambridge: Harvard University Press, 1993.

MARCO Civil da Internet: seus direitos e devere na rede. [s.d.]. Disponível em: marcocivil.com.br; Acesso em: 27 abr. 2014.

MARTÍN-BARBERO, Jesús. Saberes hoje: disseminações, competências e transversalidades. In: RIBEIRO, Ana Paula Goulart; HERSCHMANN, Micael (Org.) Comunicação e história: interfaces e novas abordagens. Rio de Janeiro: Mauad X; Globo Universidade, 2008. p.237-252.

MONIOT, Henri. A história dos povos sem história. In: LE GOFF, Jacques; NORA, Pierre (Org.) História: novos problemas. 4.ed. Rio de Janeiro: Francisco Alves, 1995. p.99-112.

MOREIRA, Silvia Cristina Gonçalves. Música na escola sob a batuta do educador: reflexões acerca do ensino de música como uma das possíveis tarefas do professor de séries iniciais do ensino fundamental. Trabalho de Conclusão de Curso (Graduação em Pedagogia) - Universidade Estadual de Maringá. Maringá, PR, 2012.

POPPER, Karl. A lógica da pesquisa científica. São Paulo: Cultrix, 1972.

PRETI, Oreste. Autonomia do aprendiz na educação a distância: significados e dimensões. In: (Org.) Educação a Distância: inícios e indícios de um percurso. Cuiabá: UFMT/NEAD, 1996. p.15-56.

SANTAELLA, Lucia. Matrizes da linguagem e pensamento: sonora, visual, verbal. 3 . ed. São Paulo: Iluminuras; Fapesp, 2005.

SANTAELLA, Lucia; NÖTH, Winfried. Imagem: cognição, semiótica, mídia. São Paulo: Iluminuras, 2008. 
SANTOS, Boaventura de Sousa. Um discurso sobre as ciências na transição para uma ciência pós-moderna. Estudos Avançados, v.2, n.2, maio-ago. 1988.

SILVA, Ana Cristina Teodoro da. Comunicar e educar como signos recíprocos. In: SILVA, A. C. T. da; NEVES, Fátima Maria; MESTI, Regina Lúcia (Org.) Educação, comunicação e mídia. Maringá: Eduem, 2009. p.11-20.

SILVEIRA, R. L. B. L. A importância do tutor no processo de aprendizagem a distância (EAD). Revista Iberoamericana de Educación [Online], México, v.35, 2005.

THE SLOW science manifesto. 2010. Disponível em: slow.science.org; Acesso em: 27 abr. 2014.

\section{NOTAS}

${ }^{1}$ Contudo, é válido ressaltar que, no Brasil, o Ministério da Educação e Cultura (MEC) a partir do Decreto no 5.622 de 19 de dezembro de 2005, exige que os cursos de EAD não sejam totalmente virtuais, de forma que certas atividades devem ser realizadas em polos presenciais, como avaliações, estágios, defesas de trabalhos de conclusão de cursos e laboratórios de ensino.

${ }^{2}$ Isso tem gerado reações, como o movimento alemão denominado slow science, que afirma a necessidade de a ciência ser elaborada a partir de um tempo de maturação das ideias. Cf. THE SLOW science manifesto, 2010.

Artigo recebido em 30 de maio de 2014. Aprovado em 27 de junho de 2014. 